\title{
Guillain-Barre Syndrome Following Dengue Fever in Adult Patient
}

\author{
QURESHI NK, ${ }^{1}$ BEGUM A, ${ }^{2}$ SAHA PR, ${ }^{3}$ HOSSAIN MI ${ }^{3}$
}

\begin{abstract}
:
Guillain-Barre syndrome is a post infectious ascending, usually demyelinationg polyradiculoneuropathy. Dengue fever as an antecedent infection in GBS is uncommon. A 39-year-old female presented with acute flaccid weakness of both upper and lower limbs which developed in ascending and progressive fashion following a febrile illness of three days. During work-up IgM for dengue virus was found positive. Diagnosis of Guillain-Barre syndrome was made based on neurologic manifestations, the typical CSF findings and pattern of electrophysiological study and exclusion of other pathologies. Patient was treated with intravenous immunoglobulins. During the course of illness, she developed lower motor neuron type trigeminal, facial, glossopharyngeal, vagus and hypoglossal nerve palsy and autonomic involvement. She had significant recovery and was able to talk, eat and walk six weeks later. Dengue is endemic in Bangladesh. Post dengue GuillainBarre syndrome in adult, as shown in previous reports, should now be considered in the part of spectrum of neurological complications of this infection.
\end{abstract}

Keyword: Guillain-Barre Syndrome (GBS), Dengue Fever.

\section{Introduction:}

Guillain-Barre syndrome (GBS) or Acute inflammatory demyelinating polyneuropathy (AIDP) is a post infectious ascending, usually demyelinating, polyradiculoneuropathy accompanied by areflexia, motor paralysis, and elevated CSF total protein without pleocytosis. ${ }^{1}$ Sensory symptoms are less conspicuous than motor ones, but distal paresthesias and dysesthesias are common, and many patient suffers from neuropathic or radicular pain. Autonomic disturbances are also common, which may be severe, and sometimes lifethreatening. ${ }^{2}$ Recent infections with Campylobacter jejuni, Cytomegalo virus, Epstein-Barr virus, Mycoplasma pneumonia, HIV are known commonly to cause GBS. $3,4,5$

Dengue is an acute febrile infectious disease caused by arboviruses belonging to the flavivirus family and are transmitted by two species of mosquitos, the Aedes aegypti and the Aedes albopictus. One hundred million cases of dengue fever are reported yearly by the WHO. ${ }^{6}$ Epidemics of dengue are being seen in almost all countries within the tropical belt including Bangladesh and its increasing

1. Specialist, Department of Medicine, United Hospital Limited, Dhaka, Bangladesh.

2. Associate Consultant, Department of Medicine, United Hospital Limited, Dhaka, Bangladesh.

3. Consultant, Department of Medicine, United Hospital Limited, Dhaka, Bangladesh.

Correspondence: Dr. Nazmul Kabir Qureshi, MD (EM), Specialist, Department of Medicine, United Hospital Limited. Plot 15, Road 71, Gulshan, Dhaka 1212, Bangladesh. Email: qureshinaz@yahoo.com incidence has been linked to overcrowding and increasing travel. ${ }^{7}$ Dengue fever as an antecedent infection in GBS is uncommon and some studies and case reports called attention to the possible association between dengue and $\mathrm{GBS}^{8,9}$. We report a case of 39 -year-old female seen at United Hospital limited, Dhaka who developed GBS in the course of Dengue fever.

\section{Case report:}

A 39-year-old lady was admitted at United Hospital Limited, Dhaka on August 19, 2011, with the complains of severe pain in the left side of lower back and upper thigh of both lower limbs for the last 4 days, followed by weakness of both lower limbs and the feeling of numbness in both lower and upper limbs for one day. Pain aggravated on movement and got some relief with NSAID. A week ago, she had high grade continued fever of three days duration which was associated with generalized body ache, headache, retroorbital pain with no rash or muco-cutaneous bleeding. There was no history of trauma, recent vaccination, tuberculosis. She could pass urine without any difficulty and she had been suffering from constipation during the course of this illness.

On physical examination, she was conscious, oriented with normal vital parameters. Motor function examination revealed hypotonia with reduced power in all four limbs and lower limbs involvement was more pronounced as compared to upper limbs. Superficial and deep tendon reflexes were absent. Her gag reflex was present. Sensory function was intact. She has no diplopia and her vision was normal. 
Provisionally she was diagnosed as a case of ascending progressive polyneuropathy, most likely Guillein Barre syndrome.

Initial laboratory workup (19/8/2011) revealed normal hemoglobin, ESR, WBC count. Her serum electrolyte, liver function tests, renal function tests, chest X-ray PA view and blood culture was negative. Serology for HIV, Hepatitis B and C, Malaria work-up, ANA were negative. Dengue IgM was positive. CSF study was done on 20/8/2011 which revealed an albuminocytological dissociation ( $10 \mathrm{ml}$ crystal clear CSF fluid. RBC: nil, WBC: $03 / \mathrm{cmm}, \mathrm{N} \%$ : 0\%, lymphocyte: $100 \%$, protein: $101.56 \mathrm{mg} / \mathrm{dl}$, Glucose: $4.22 \mathrm{mmol} /$ L(RBS was $6.3 \mathrm{mmol} / \mathrm{L}$ ), Gram's stain: no bacteria or fungus, AFB: not found. CSF for C/S: no growth, CSF for fungus: no growth up to 7 days at $37^{\circ} \mathrm{C}$ ). Stool for Campylobacter jejuni was negative. On 22/8/2011 Electrophysiological study of nerves was done which revealed demyelinating and axonal polyneuropathy in lower and upper limbs. Finally a diagnosis of GBS associated with dengue fever was made.

Patient was treated with a course of intravenous immunoglobulins at $0.4 \mathrm{gm} / \mathrm{kg} /$ day for 5 days. For prophylaxis of venous thrombosis and pulmonary emboli, low-molecularweight heparin was given. On admission there was no cranial nerve involvement but two days later, during the course of hospital stay, she developed lower motor neuron type trigeminal, facial, glossopharyngeal, vagus and hypoglossal nerve palsy. Her upper limbs involvement became more pronounced during the course of illness. Four days later she developed urinary incontinence and autonomic involvement (resting tachycardia, gustatory sweating). Other systemic examinations revealed no abnormality during the course of hospital stay. With adequate treatment and supportive measures patient made a significant recovery and was able to talk, eat and walk six weeks later.

\section{Discussion:}

Dengue is the most common human arboviral infection. It was considered as a sporadic disease during nineteen century only causing epidemics at intervals. However, currently dengue is considered the most common viral disease transmitted by mosquitoes across the globe that is endemic in 112 countries and in tropical countries annual outbreaks have occurred since $1986 .{ }^{10}$ Usually the disease has a self limiting course and common clinical-biochemical features are fever, intense muscle pain, retro-orbital headache, rash, hypotension, vomiting, thrombocytopenia, elevated serum transaminases, elevated partial thromboplastin time, hemoconcentration, leucopenia etc.

Neurological menifestations associated with dengue fever has been reported from 25 different countries from Asia-
Pacific, the Americas, the Mediterranean and Africa. Cases have been reported among ages ranging from 3 months to 60 years in both sexes. ${ }^{11}$ However, there is a greater incidence among children. The incidence of neurological symptoms and complications among dengue patients varied from $1 \%$ to $25 \%$ of all dengue admissions. ${ }^{7,11,12}$ Neurological manifestations reported in literature include depression, convulsion, nuchal rigidity, encephalitis, encephalopathy, focal neurological deficit, peripheral facial paralysis, flaccid paraparesis, transverse myelitis, hemifacial spasm, GuillainBarre syndrome, pyramidal tract sign etc. ${ }^{13,14,15,16,17 .}$

Several previous reports have described Guillain-Barre syndrome in patients with dengue. Most of the reported cases were found among children. ${ }^{18-21}$ and first report of post-Dengue GBS in children is referred in the study of Sulekha et al. ${ }^{20}$ Few cases of post-Dengue GBS were reported among adults. CHEW et al. reported two cases of postDengue GBS. ${ }^{22}$ Their first case was a 43-year-old woman with severe GBS presenting with tetraparesis and respiratory distress. She required assisted ventilation and immunomodulation treatment. The second case was a 51year-old man with bilateral facial palsy and numbness of extremities but no weakness. He recovered without treatment. Gupta et al. ${ }^{23}$ reported a 24 -year-old male presenting with acute flaccid paralysis of both lower limbs following dengue. Patient was treated with intravenous immunoglobulins and had a rapid and complete recovery. ${ }^{22}$

In all previous reports, the onset of GBS occurred after recovery of the initial infection. The mechanism for postDengue GBS is not fully known. There is evidence that this is an immune-mediated neurological disease. ${ }^{24}$ Proinflammatory substances that participate in immune response to dengue virus (TNF-á, complement, interleukins) may have important role in the pathogenesis of GBS which can establish the relationship between two conditions. ${ }^{25}$ Immune response evoked by dengue fever may in turn cross-react with peripheral nerve components because of sharing of crossreactive epitopes (molecular mimicry). This immune response can be directed towards the myelin or axon of peripheral nerves. $^{26}$

The most important aspect of the management of GBS is good quality intensive care. Several randomized clinical trials indicate that plasma exchange is more effective than supportive treatment alone in reducing the median time taken for patients to recover. ${ }^{27,28}$ Intravenous immunoglobulin appears as effective as plasma exchange and may be superior with fewer side-effects. ${ }^{29}$ Corticosteroids alone do not alter the outcome of GBS, and there is insufficient evidence that their use in combination with immunoglobulin is effective. ${ }^{30}$ 
Other treatments such as CSF filtration remain experimental and unproven. ${ }^{31}$

In the present case, positive dengue specific IgM antibody test is an evidence of active infection or recently acquired disease. Neurologic manifestations, the typical CSF findings and pattern of electrophysiological study were consistent with the diagnosis of GBS. GBS developed about a week after the initial manifestation of dengue. Patient was treated with intravenous immunoglobulin.

\section{Conclusion:}

Dengue is a common infection in Bangladesh but other than encephalopathy its neurological various complications have rarely been addressed with importance. GBS should now be considered in the part of spectrum of neurological complications of this infection.

\section{Conflict of Interest : None}

\section{References:}

1. Hauser SL, Asbury AK. Guillain-Barrée Syndrome and Other Immune-Mediated Neuropathies. In: Fauci SA, Braunwald E, Kasper DL, Hauser SL, Longo DL, Jameson JL, Loscalzo J. Harrison's Principles of Internal Medicine 17th ed. The McGraw Hill 2009. Chap. 380, p. 2667

2. Aminoff MJ, Kerchner GA. Nervous System Disorders. In: McPhee SJ, Papadakis MA, Rabow MW. Current Medical Diagnosis \& Treatment $201150^{\text {th }}$ ed.. The McGraw Hill 2011. Chap 24, P.982

3. Hughes RA, Hadden RD, Gregson NA, Smith KJ. Pathogenesis of Guillain-Barre syndrome. J Neuroimmunol 1999;100:74-97

4. Jacobs BC, Rothbarth PH, van der Meche FG, et al. The spectrum of antecedent infections in Guillain-Barre syndrome: a case-control study. Neurology 1998;51: 1110-1105

5. Thornton CA, Latif AS, Emmanuel JC. Guillain-Barre syndrome associated with human immunodeficiency virus infection in Zimbabwe. Neurology 1991;41:812-5

6. Channa R, Wasay M. Central nervous system involvement in dengue viral infection. Pakistan J Neurol Sci 2006;1(2):84-8.

7. Solomon T, Dung NM, Vaughn DW, Kneen R, Thao LT, Raengsakulrach B, et al. Neurological manifestation of dengue infection. Lancet 2000;355:1053-9

8. Santos NQ, Azoubel AC, Lopes AA, Costa G, Bacellar A. Guillain-Barre syndrome in the course of dengue: case report. Arq neuropsiquiatr 2004;62:144-6

9. Esack A, Teelucksingh S, Singh N. The Guillain-Barre syndrome following dengue fever. West Indian Med J 1999; 48:36-7
10. Gubler D. The emergence of epidemic dengue fever and dengue hemorrhagic fever in the Americas: a case of failed public health policy. Rev Panam Salud publica 2005;17: 221-4

11. Thakare J, Walhekar B, Banerjee K. Hemorrhagic manifestations and encephalopathy in cases of dengue in India. Southeast Asian J Trop Med Public Health 1996;27: 471-5

12. Kankirawatana $\mathrm{P}$, Chokephaibulkit K, Puthavathana $\mathrm{P}$, Yoksan S, Apintanapong S, Pongthapisit V. Dengue infection presenting with central nervous system manifestation. J Child Neurol 2000;15: 544-7

13. Lum LC, Lam SK, Choy YS, George R, Harun F. Dengue encephalitis: a true entity? Am J Trop Med Hyg 1996; 54 : 256-9

14. De Souza LJ, Martins AL, Paravinidi PC, Nogueira RM, Gicovate Neto C, Bastos DA, et al. Hemorrhagic encephalopathy in dengue shock syndrome: a case report. Braz J Infect Dis 2005;9:257-61

15. Patey O OL, Breuli J, Lafaix C. Unusual neurologic manifestations occurring during dengue fever infection. Am J Trop Med Hyg 1993;48:793-802

16. Ratageri VH, Shepur TA, Wari PK, Chavan SC, Mujahid IB, Yergolkar PN. Clinical profile and outcome of dengue fever cases. Indian J Pediatr 2005;72:705-6

17. Yeo PS, Pinheiro L, Tong P, Lim PL, Sitoh YY. Hippocampal involvement in dengue fever. Singapore Med J 2005;46: $647-50$

18. Sulekha C, Kumar S, Philip J. Guillain-Barre syndrome following dengue fever: report of 3 cases. Indian Pediatr 2004; 41:948-50

19. Cunha Matta AP, Soares-Moreno SA, Cardoso de Almeida A, Aquilera de Freitas V, Carod-Artal FJ. Complicaciones neurologicas de la infeccion por el virus del dengue. Rev Neurol 2004;39:233-7

20. Shah I. Dengue presenting as Guillain-Barre syndrome. Dengue Bulletin 2007;31:166-8

21. Goncalves E. Acute inflammatory demyelinating polyradiculoneuropathy (Guillain-Barre syndrome) following dengue fever. Rev Inst Med Trop Sao Paulo 2011;53(4):223-5

22. Chew NK, Goh KJ, Omar S, Tan CT. Guillain-Barre syndrome with antecedent dengue infection- a report of two cases. Neurol J Southeast Asia 1998;3:85-6

23. Gupta P, Jain V, Chatterjee S, Agarwal AK. Acute inflammatory motor axonopathy associated with dengue. Journal Indian Academy of Clin Med 2009;10(1 \&2):58-9 
24. Soares CN, Cabral-Castro MJ, Peralta JM, de Freitas MR, Zalis M, Puccioni-Sohler M. Review of etiologies of viral meningitis and encephalitis in a dengue endemic region. $\mathrm{J}$ neurol Sci 2011;303:75-9

25. Puccioni-Sohler M, Soares CN, Papaiz-Alvarenga R, Castro MJ, Faria LC, Peralta JM. Neurologic dengue manifestations associated with intrathecal specific immune response. Neurology 2009;73:1413-7

26. Hahn AF. Guillain-Barre syndrome. Lancet 1998;352:635-41.

27. Farkkila M, Kinnunen E, Haapanen E, Iivanainen M. Guillain-Barre' syndrome: quantitative measurement of plasma exchange therapy. Neurology 1987;37:837-40
28. Greenwood RJ, Newsom-Davis J, Hughes RA, et al. Controlled trial of plasma exchange in acute inflammatory polyradiculoneuropathy. Lancet 1984; 1:877-9

29. van der Meche' FGA, Schmitz PI. A randomized trial comparing intravenous immune globulin and plasma exchange in Guillain-Barre' syndrome. Dutch Guillain-Barre' Study Group. N Engl J Med 1992; 326:1123-9

30. Winer JB. Treatment of Guillain-Barre syndrome. Q J Med 2002; 95:717-721

31. Wollinsky $\mathrm{K}$, Hulser $\mathrm{P}$, Brinkmeier $\mathrm{H}$, et al. CSF filtration is an effective treatment of Guillain-Barre' syndrome: a randomized clinical trial. Neurology 2001; 57:774-80 